\title{
Pyroptosis and neurological diseases
}

\author{
Zhen Xie ${ }^{1,2}$, Gang Zhao ${ }^{1}$ \\ ${ }^{1}$ Department of Neurology, Xijing Hospital, Forth Military Medical University, Xi'an 710032, Shaanxi, China \\ ${ }^{2}$ Department of Neurology, Shaanxi Provincial People's Hospital, Xi'an 710068, Shaanxi, China
}

\section{A B S T R A C T}

Pyroptosis is a new process of programmed cell death, which has been discovered and confirmed in recent years. Its cardinal features include activation of caspase- 1 and a massive release of inflammatory cytokines (interleukin (IL)-1 $\beta$, IL-18), etc. The morphological characteristics, occurrence and regulatory mechanisms of the pyroptosis greatly, differ from other cell death mechanisms such as apoptosis and necrosis. It has already been proven that pyroptosis participates and plays an important role in a wide range of neuronal diseases. Here, we review the current understanding of the pyroptosis and its roles in neurological diseases.

Key words: Caspase-1, inflammasome, interleukin-1 $\beta$, interleukin-18, neurological diseases, pyroptosis

\section{INTRODUCTION}

Cell death is a critical and inevitable phase common to all cell types. A deeper understanding of cell death in its form and nature is critical to shed new light on the emergence, development and treatment of diseases. Many different types of cell death patterns have been discovered in the last years; among that pyroptosis is one of the most recent. It is now widely accepted that this mechanism contributes to the development of neurological diseases. In this review, we first describe the definition of the pyroptosis and its basic mechanisms and discuss how pyroptosis and its relevant molecules participate in neurological diseases and their progression.

\section{THE HISTORY OF PYROPTOSIS AND ITS CHARACTERISTICS}

The understanding of cell death has changed a lot through decades. Nowadays we believe that cell death can be roughly divided into necrosis and programmed cell death, the latter one, including apoptosis, oncosis, autophagy, etc., as well as pyroptosis that will be discussed in this review.

\begin{tabular}{|l|l|}
\hline \multicolumn{2}{|c|}{ Access this article online } \\
\hline Quick Response Code: & \\
\hline & Website: \\
\hline & www.nnjournal.net \\
\cline { 2 - 3 } & \\
\hline
\end{tabular}

Pyroptosis was first observed in 1992 when Zychlinsky et al. described that Shigella flexneri can induce programmed cell death in macrophage, but this process was mediated by a caspase- 1 , and the iconic molecule in apoptosis, caspase-3, was not apparently involved. This observation suggested that such programmed cell death was different from apoptosis. ${ }^{[1]}$ Subsequent studies confirmed that in $S$. flexneri specific caspase-1 blocker Ac-YVAD-CHO inhibited programmed cell death of macrophages, whereas caspase-1 knockout could protect macrophages from death following $S$. flexneri infection. ${ }^{[1,2]}$ In contrast, caspase-3 specific blockers and caspase-3 knockout macrophages did not show any effects. ${ }^{[3]}$ Then, in 2001, Cookson and Brennan found a type of caspase-1 dependent cell death in Salmonella infected macrophages, and for the first time named it "pyroptosis", its meaning deriving from the Greek root pyro (fireworks) and ptosis (to-sis) (death). ${ }^{[4]}$

In the process of the pyroptosis, activated caspase- 1 mediates massive generation of pro-inflammatory cytokines, interleukin (IL)-1 $\beta$, IL-18, ${ }^{[5]}$ leading to cell morphological changes similar to apoptosis, such as nucleus pycnosis, DNA fragmentation and TUNEL staining positivity, etc. However, in contrast to apoptosis, in pyroptotic cell, the integrity of the cell membrane is not preserved and micro-pores with diameter about 1-2 $\mathrm{nm}$ are formed on it, resulting in potassium efflux, intracellular and extracellular ion imbalance, cell swelling and rupture. Meanwhile, the pro-inflammatory cytokines and cytoplasmic components are released to the extracellular space, causing focal inflammation and cell death. ${ }^{[6]}$

Corresponding Author: Prof. Gang Zhao, Department of Neurology, Xijing Hospital, Fourth Military Medical University, No. 169 Changle West Road, Xi'an 710032, Shaanxi, China. E-mail: xiezhenhh@163.com 
Lately, researchers realized that a variety of bacterial and nonbacterial stimuli (e.g. substance related to autoimmune diseases and cardiovascular and cerebrovascular diseases ${ }^{[7-9]}$ ) can drive programmed cell deaths similar to pyroptosis. Meanwhile, in addition to macrophages, there are a variety of cells (such as dendritic cells, etc.) undergoing programmed death involving caspase-1 activation, thereby different from caspase-3 mediate apoptosis. Moreover, cells undergoing pyroptosis exhibit a series of cellular changes from complete necrosis to complete the apoptosis..$^{[10-12]}$

\section{MECHANISIMS OF PYROPTOSIS}

Pyroptosis and caspase-1 are closely associated. Caspase family is a group of proteases with high homology, and it can be divided into two categories according to its relationship with apoptosis and pyroptosis. One includes apoptosis-related proteases, for instance caspase-3, the executor of apoptosis, and also caspase-2, 6, 7, 8, 9, 10 etc. Caspase-3 is activated by co-action of caspase-2, 6, 7, 8, 9, 10 etc., and activated caspase- 3 could induce DNA dissolution, proteolysis, and downstream events leading to apoptosis. The second is inflammation-associated proteases, including caspase- 1 and caspase- $4,5,11,12,13,14$ etc., taking part in cytokines-mediated inflammatory response. ${ }^{[13]}$ Caspase- 1 is not involved in apoptosis, but represents the key factor in pyrotosis. Caspase- 1 is an IL- $1 \beta$ converting enzyme. Pro-caspase-1 does not have biological activity when produced. Its molecular weight is $45 \mathrm{kDa}$, constituted by the three domains, including the caspase activation and recruitment domains (CARD) structure in $\mathrm{NH}_{2}$-terminal, a large subunit about $20 \mathrm{kDa}$, and a small subunit about $10 \mathrm{kDa}$. Then, pro-caspase- 1 is converted into heterodimer in the cytoplasm, and further assembled into biologically active tetrameric caspase- $1{ }^{[13]}$ This activation process is regulated by a multi-protein complex in the cytoplasm named inflammasome. ${ }^{[14]}$

Inflammasome is a multi-protein complex composed by NOD-like receptors (NLRs), proteins containing NATCH, leucine-rich repeat and PYD domains (NLRP1 NLRC4 NLRP3 NAIP5 and NLRC5), or absent in melanoma 2 (AIM2), or Caspase-1 etc. Some of the inflammasomes also contain apoptosis-associated speck-like proteins containing CARD (ASC). Recent studies have confirmed that retinoic acid-inducible gene I (RIG-I), one of the receptors of some RNA viruses, can form inflammasome with ASC, without the participation of NLRs. ${ }^{[15]}$ Under the regulation of inflammasome, pro-caspase- 1 is activated, promoting the processing and maturation of pro-inflammatory factors such as IL-1 and IL-18.
NOD-like receptors are one of the pattern recognition receptors (PRR); they can be assembled into inflammasome under the stimulation of pathogens or other dangerous signals. According to different NLRs, the inflammasome can be classified into four types, NLRP-1, 3, 4 Ice Protease-Activating Factor (IPAF), 5. During pathogen stimulation, effector domains of NLRs are exposed to activating caspase-1 through CARD-CARD and PYD-PYD interactions or with the help of ASC directly. Different types of NLRs respond to different stimuli. NALP3 is sensible to perforin, extracellular adenosine triphosphate (ATP), urate crystals, DNA and RNA in virus and ultraviolet. IPAF is sensible to extracellular pathogens, such as Pseudomonas, and intracellular pathogens such as Salmonella, Listeria, Shigella, Legionella bacteria. Legionella also needs the help of NALP5-5 to activate caspase-1. ${ }^{[16,17]}$ AIM plays an important role in viral infections; its function is to identify DNA cytoplasm. It is a cytoplasmic DNA transducer, one of PRRs sensible to extrinsic DNA. It belongs to HIN-200 family, with a PYD domain in amino-terminal and an HIN-200 domain in carboxy-terminal. ${ }^{[18]}$ In virus-infected cells, AIM2 and caspase-1 can form inflammasome to induce innate immunity and resist intracellular bacteria and DNA viruses. ${ }^{[19]}$ RIG-I also binds to the adaptor ASC to trigger caspase-1-dependent inflammasome activation by a mechanism independent from CARD and NLRP3 in RNA infection. ${ }^{[15]}$ The effects of ASC are to combine caspase-1 and NLRP1, NLRP3, AIM2, RIG-I together. The mechanism is mediated by the PYD domain in the carboxyl terminus of ASC combined with PYD domain in NLRP1 NLRP3 and AIM, with the CARD domain in N-terminal of ASC combined with pro-caspase-1's CARD domain. In addition, ASC can be assembled into ASC dimer without the participation of NLRs, and ASC dimer can activate caspase-1 directly. This ASC dimer has been named Pyroptosome recently. ${ }^{[20]}$

The activators of the inflammasomes can be divided into two categories: pathogen associated molecular patterns activate a host-defense reaction, and damage associated molecular patterns activate a self-defense mechanism in response to danger signals. ${ }^{[21]}$ Activators include bacteria, virus, fungus, protozoa, microbial proteins, crystalline urea, RNA, Alum, ATP, potassium efflux, fatty acids, A $\beta$, and most recently, degraded mitochondrial DNA. ${ }^{[22-24]}$ Overall the assembly and activation of inflammasomes are cell-type and stimulus-specific. ${ }^{[25,26]}$

With inflammasome, pro-caspase- 1 is activated to caspase-1. Its function includes conversion of the pro-IL$1 \beta$ and pro-IL-18 into active IL-1 $\beta$ and IL- 18 . When bound to their receptors, IL-1R and IL-18R, they lead to nuclear factor- $\mathrm{\kappa B}$ dependent gene transcription. ${ }^{[27,28]} \mathrm{IL}-1 \beta$ is a key molecule in inflammasome initiation and IL-18 can 
regulate the function of interferon- $\gamma$ in T-cell and natural killer cell. ${ }^{[27,28]}$ Finally, they can recruit and activate other immune cells and induce the synthesis of other inflammatory cytokines, chemokines, and adhesion molecules, expanding local inflammation response. ${ }^{[13]}$ Moreover, cell membrane integrity is destroyed by micro-pores formation on it, which is caused by caspase-1, IL-1 $\beta$ and IL-18. These micro-pores lead to a series of pyroptoic processes such as cytoplasm release, cell osmotic lysis and inflammatory reaction. ${ }^{[13,29]}$ In addition, during the process of the pyroptosis, caspase-1 is involved in chromosomes and DNA degradation. A specific endonuclease is activated by caspase-1. Once activated, this endonuclease can mediate degradation of DNA, which differs from the DNA degradation occurring in apoptosis. ${ }^{[29]}$ More experiments have confirmed that the degradation of cytoskeletal proteins is also associated with pyroptosis and that this process is related with treatment and processing of substrates by caspase- $1 .{ }^{[30]}$

\section{PYROPTOSIS AND NEUROLOGICAL DISEASES}

Pyroptosis is closely related to neurological diseases. Pyroptosis and its relative mechanisms participate in acute and chronic aseptic inflammation in the nervous system. Our immune system could recognize disease-associated molecules through PRR. In the central nervous system (CNS), PRR are expressed mainly on microglial, macrophages and astrocytes. They are distributed on the surface of membranes to recognize extracellular signals (i.e. toll like receptors), or in the cytoplasm to transmit intracellular signal (i.e. NLR receptor).

There are several NLRP1 and NLRP3 inflammasomes expressed in the nervous system. ${ }^{[31]}$ Mouse microglial cells could express NLRP3 and NLRP4 inflammasome, and they can respond to stimulation of dangerous signals. ${ }^{[32-35]}$ Additional evidences indicate that inflammasomes can be expressed in nonmyeloid cells of the nervous system. Meanwhile, many studies have proven that caspase-1, IL-1 $\beta$ and IL-18 could be activated and NLRs inflammasomes can be assembled in neurons under stress conditions. ${ }^{\left[{ }^{36-40]}\right.}$ In addition, recent studies have also shown that NLRP2 inflammasomes can be expressed in astrocytes. ${ }^{[41,42]}$ In the CNS, microglia, astrocytes and neurons can all undergo pyroptosis and express its related downstream molecules and receptors, thus taking part in the immune reaction to local inflammation..$^{[27,28,43]}$ In fact, in diseases such as viral encephalitis, stroke, Alzheimer's disease (AD) and multiple scleroses (MS), many studies have shown massive expression of IL-1 $\beta$ and IL-18 etc., in the nervous system. ${ }^{\left[{ }^{[3,44-46]}\right.}$ However, further investigation is required to elucidate mechanisms.
Pryoptosis and infection diseases in the nervous system Pyroptosis and its related molecules may participate in the development of nervous system encephalitis and meningitis. These phenomena have a different prognosis in bacterial and virus infection. For example, in Streptococcus pneumoniae meningitis participation of NLRP3 inflammasome aggravate the damage caused by the disease. IL-1 $\beta$ and IL-18 are not involved in growth inhibition of bacteria, but contribute to exacerbate the inflammatory response in the nervous system. ${ }^{[47-49]}$ Some studies indicate that mouse microglia and peripheral macrophages infected with Staphylococcus aureus, Mycobacterium tuberculosis and Legionella pneumophila in vitro may activate the NLRP3 or NLRP4 inflammasome thus inducing pyroptosis. ${ }^{[32,50,51]}$

However, in viral encephalitis caused by West Nile virus (WNV), influenza A virus, and herpes simplex virus, IL-1 $\beta$ and IL-18 can increase survival rate of neurons by inhibiting viremia. ${ }^{[39,52-54]}$ In WNV encephalitis, it was observed that the production and release of IL-1 $\beta$ increased in neurons, and IL- $1 \beta$ inhibited the replication of WNV. The survival rate decreased in NLRP3 and ASC knockout mice infected by WNV. ASC knockout mice can experience excessive immune response after WNV infection, and this will contribute to neuronal damage. ${ }^{[39]}$ Japanese encephalitis virus can activate NLRP3 inflammasome in microglia, promote the release of IL- $1 \beta$ and IL-18. ${ }^{[34]}$ In CMV retinitis, it was also observed microglia death through pyroptosis pathway. ${ }^{[55]}$ But their influence on prognosis is not yet clear.

Pyroptosis and acute aseptic disease in the nervous system In acute aseptic nervous system damage (such as stroke or traumatic brain injury), local autoimmune activation can cause nerve injury. Studies have demonstrated that mice with caspase-1 defection may have a certain resistance to stroke, which indicated that pyroptosis and its relative mechanisms exacerbate brain damage in stroke ${ }^{[56]} \mathrm{IL}-18$ knockout mice didn't show any kind of protective effects in stroke. In contrast, some IL-1 receptor antibodies could still have a protective effect(s) to neurons, even after the occurrence of stroke. This suggests that the protective effect is not only dependent on IL-1 $\beta$, but also IL-1 $\alpha$. IL- $1 \beta$ and IL- $1 \alpha$ defected mice have a better resistance to stroke. ${ }^{[57]}$ Although IL-1 $\alpha$ and caspase- 1 do not have a direct relationship, caspase-1 may have an indirect protective effect (s) by influencing IL-1R2 and caspase-1 dependent nonclassical secretion system. ${ }^{[58,59]}$ Meanwhile, inflammasome also been observed in a study of excitotoxic injury in kainate model..$^{[38]}$

Similarly, in the rodent model, antibodies for ASC or NLRP1 can reduce injury of brain trauma or stroke. ${ }^{[60,61]}$ 
A study demonstrated that MCAO could induce NLRP1 and NLRP5 inflammasome expression in rat neurons. ${ }^{[62]}$ Traumatic brain injury patients with higher NLRP1 level in cerebrospinal fluid may have a worse prognosis. ${ }^{[63]}$

Pyroptosis and chronic aseptic disease in the nervous system Chronic aseptic diseases have a great influence on the structure and function of CNS. MS is a typical one. In MS, T cells and macrophages move into CNS. A study of NLRP3 and ASC knockout mice found that autoimmune encephalitis depends on the NLRP3 inflammasome. ${ }^{[64,65]}$ Inhibition of NLRP3 expression and subsequent reduction of IL-1 $\beta$ and IL-18 secretion can restrain the activation of $\mathrm{T}$ cell and its migration into CNS, so as to mitigate the autoimmune encephalitis. ${ }^{[64-66]}$

In cuprizone-induced CNS autoimmune inflammation and demyelination model, IL-1 $\beta$ and IL-18 play a different role in demyelination. IL-1 $\beta$ knockout mice have a similar MS phenotype to wild-type animals, but the process of remyelination is delayed. This suggests that IL-1 $\beta$ may promote recovery from MS. ${ }^{[67]}$ In contrast, in IL-18 knockout mice, the disease is reduced, and the speed of myelination is faster. ${ }^{[68]}$ In NLRP3 knockout mice, the onset is delayed in cuprizone induced demyelination, but the extent of remyelination is identical to those of wild-type. ${ }^{[68]}$ Therefore, the pyroptosis and its relative mechanisms are involved in the pathological process, and IL-1 $\beta$ and IL-18 have opposite effects on the recovery of the disease.

Besides, accumulating evidences suggest that the immune system participates in the process of amyotrophic lateral sclerosis (ALS), AD, Parkinson's disease and Huntington's disease. ${ }^{[69]}$ Amyloid beta is the main components of senile plaques in $\mathrm{AD}$, it is also one of the first molecules found to be involved in the relationship between chronic aseptic diseases and inflammasome. ${ }^{[33]}$ LPS sensitized macrophages exposed to fibrillar amyloid-beta activate caspase- 1 and induced the release of IL-1 $\beta$. This process is dependent on NLRP3, endosomal rupture and cathepsin B release. ${ }^{[33]}$ A similar phenomenon was found in $\alpha$-synuclein in Parkinson's disease and prion protein. ${ }^{[70,71]}$ However, to elucidate the function of IL-1 $\beta$, different studies have reached different conclusions. Some indicate that in Il-1 $\alpha$ knockout mice, injecting human amyloid beta into encephalocoele would activate microglia, so as to reduce neuron survival rate. ${ }^{[72]}$ However, other experiments show that over-expression of IL-1 $\beta$ in hippocampus could reduce senile plaque formation by recruiting macrophage. ${ }^{[73]}$

In ALS, mutation of superoxide dismutase 1 (SOD1) leading to accumulation of toxic protein is one of the main pathogenic factors. Mutant SOD1 in cultured microglia activates caspase- 1 and the amount of subsequent IL-1 $\beta$ is proportional to the concentration of mutant SOD1 added. In this process, the activation of inflammasome requires endosomal rupture and participation of ASC. However, it is not clear which specific inflammasome is involved. Caspase-1 or IL-1 $\beta$ defect would improve the survival rate of mice expressing toxic SOD1, which indicates that pyroptosis and its relative mechanisms could exacerbate ASL. ${ }^{[74]}$

\section{CONCLUSION}

Recent findings of the pyroptosis and inflammasome have provided insight into a new mechanism that may contribute to neuronal and glial cell death during neurological diseases. Multiple potential targets upstream and downstream of pyroptosis signaling and targeting its expression, assembly, activity and products, may pave the way for newly therapeutic drugs that may rescue inflammation in neurological diseases. However, it is important to note that although some aspects of the inflammatory response will not only exacerbate brain injury, it is also likely that other components will provide a beneficial contribution to brain recovery. Elucidating the role of these components will represent a challenge for future research. Unquestionably, still a lot needs to be done to clarify the role of the inflammasome during the recovery phase following neurological diseases.

\section{REFERENCES}

1. Zychlinsky A, Prevost MC, Sansonetti PJ. Shigella flexneri induces apoptosis in infected macrophages. Nature 1992;358:167-9.

2. Miao EA, Leaf IA, Treuting PM, Mao DP, Dors M, Sarkar A, Warren SE, Wewers MD, Aderem A. Caspase-1-induced pyroptosis is an innate immune effector mechanism against intracellular bacteria. Nat Immunol 2010;11:1136-42.

3. Lamkanfi M, Dixit VM. Manipulation of host cell death pathways during microbial infections. Cell Host Microbe 2010;8:44-54.

4. Cookson BT, Brennan MA. Pro-inflammatory programmed cell death. Trends Microbiol 2001;9:113-4.

5. Brennan MA, Cookson BT. Salmonella induces macrophage death by caspase-1-dependent necrosis. Mol Microbiol 2000;38:31-40.

6. Fink SL, Cookson BT. Caspase-1-dependent pore formation during pyroptosis leads to osmotic lysis of infected host macrophages. Cell Microbiol 2006;8:1812-25.

7. Liu XH, Kwon D, Schielke GP, Yang GY, Silverstein FS, Barks JD. Mice deficient in interleukin-1 converting enzyme are resistant to neonatal hypoxic-ischemic brain damage. $J$ Cereb Blood Flow Metab 1999;19:1099-108.

8. Frantz S, Ducharme A, Sawyer D, Rohde LE, Kobzik L, Fukazawa R, Tracey D, Allen H, Lee RT, Kelly RA. Targeted deletion of caspase-1 reduces early mortality and left ventricular dilatation following myocardial infarction. $J$ Mol Cell Cardiol 2003;35:685-94.

9. Shi L, Chen G, MacDonald G, Bergeron L, Li H, Miura M, Rotello RJ, Miller DK, Li P, Seshadri T, Yuan J, Greenberg AH. Activation of an interleukin 1 converting enzyme-dependent apoptosis pathway by granzyme B. Proc Natl Acad Sci U S A 1996;93:11002-7.

10. Kepp O, Galluzzi L, Zitvogel L, Kroemer G. Pyroptosis - A cell death modality of its kind? Eur J Immunol 2010;40:627-30. 
11. Vanden Berghe T, Goethals A, Demon D, Bogaert P, Mak TW, Cauwels A, Mak TW, Cauwels A, Vandenabeele P. An inactivating caspase-11 passenger mutation muddles sepsis research. Am J Respir Crit Care Med 2013;188:120-1.

12. Chen X, Wu J, Lvovskaya S, Herndon E, Supnet C, Bezprozvanny I. Dantrolene is neuroprotective in Huntington's disease transgenic mouse model. Mol Neurodegener 2011;6:81.

13. Yazdi AS, Guarda G, D'Ombrain MC, Drexler SK. Inflammatory caspases in innate immunity and inflammation. $J$ Innate Immun 2010;2:228-37.

14. Duprez L, Wirawan E, Vanden Berghe T, Vandenabeele P. Major cell death pathways at a glance. Microbes Infect 2009;11:1050-62.

15. Poeck H, Bscheider M, Gross O, Finger K, Roth S, Rebsamen M, Hannesschlager N, Schlee M, Rothenfusser S, Barchet W, Kato H, Akira S, Inoue S, Endres S, Peschel C, Hartmann G, Hornung V, Ruland J. Recognition of RNA virus by RIG-I results in activation of CARD9 and inflammasome signaling for interleukin 1 beta production. Nat Immunol 2010;11:63-9.

16. Cervantes J, Nagata T, Uchijima M, Shibata K, Koide Y. Intracytosolic Listeria monocytogenes induces cell death through caspase-1 activation in murine macrophages. Cell Microbiol 2008;10:41-52.

17. Bergsbaken T, Fink SL, Cookson BT. Pyroptosis: host cell death and inflammation. Nat Rev Microbiol 2009;7:99-109.

18. Roberts TL, Idris A, Dunn JA, Kelly GM, Burnton CM, Hodgson S, Hardy LL, Garceau V, Sweet MJ, Ross IL, Hume DA, Stacey KJ. HIN-200 proteins regulate caspase activation in response to foreign cytoplasmic DNA. Science 2009;323:1057-60.

19. Rathinam VA, Jiang Z, Waggoner SN, Sharma S, Cole LE, Waggoner L, Vanaja SK, Monks BG, Ganesan S, Latz E, Hornung V, Vogel SN, Szomolanyi-Tsuda E, Fitzgerald KA. The AIM2 inflammasome is essential for host defense against cytosolic bacteria and DNA viruses. Nat Immunol 2010;11:395-402.

20. Fernandes-Alnemri T, Wu J, Yu JW, Datta P, Miller B, Jankowski W, Rosenberg S, Zhang J, Alnemri ES. The pyroptosome: a supramolecular assembly of ASC dimers mediating inflammatory cell death via caspase-1 activation. Cell Death Differ 2007;14:1590-604

21. Salminen A, Ojala J, Suuronen T, Kaarniranta K, Kauppinen A. Amyloid-beta oligomers set fire to inflammasomes and induce Alzheimer's pathology. J Cell Mol Med 2008;12:2255-62.

22. Liu L, Martin R, Chan C. Palmitate-activated astrocytes via serine palmitoyltransferase increase BACE1 in primary neurons by sphingomyelinases. Neurobiol Aging 2013;34:540-50.

23. Mathew A, Lindsley TA, Sheridan A, Bhoiwala DL, Hushmendy SF, Yager EJ, Ruggiero EA, Crawford DR. Degraded mitochondrial DNA is a newly identified subtype of the damage associated molecular pattern (DAMP) family and possible trigger of neurodegeneration. J Alzheimers Dis 2012;30:617-27.

24. Schmidt RL, Lenz LL. Distinct licensing of IL-18 and IL-1ß secretion in response to NLRP3 inflammasome activation. PLoS One 2012; 7:e45186.

25. Martinon F, Mayor A, Tschopp J. The inflammasomes: guardians of the body. Annu Rev Immunol 2009;27:229-65.

26. Schroder K, Tschopp J. The inflammasomes. Cell 2010;140:821-32.

27. Allan SM, Tyrrell PJ, Rothwell NJ. Interleukin-1 and neuronal injury. Nat Rev Immunol 2005;5:629-40.

28. Alboni S, Cervia D, Sugama S, Conti B. Interleukin 18 in the CNS. J Neuroinflammation 2010;7:9.

29. Fink SL, Bergsbaken T, Cookson BT. Anthrax lethal toxin and Salmonella elicit the common cell death pathway of caspase-1-dependent pyroptosis via distinct mechanisms. Proc Natl Acad Sci U S A 2008;105:4312-7.

30. Labbé K, Saleh M. Cell death in the host response to infection. Cell Death Differ 2008;15:1339-49.

31. Yin Y, Yan Y, Jiang X, Mai J, Chen NC, Wang H, Yang XF Inflammasomes are differentially expressed in cardiovascular and other tissues. Int J Immunopathol Pharmacol 2009;22:311-22.

32. Jamilloux Y, Pierini R, Querenet M, Juruj C, Fauchais AL, Jauberteau MO, Jarraud S, Lina G, Etienne J, Roy CR, Henry T, Davoust N, Ader F. Inflammasome activation restricts Legionella pneumophila replication in primary microglial cells through flagellin detection. Glia 2013;61:539-49.

33. Halle A, Hornung V, Petzold GC, Stewart CR, Monks BG Reinheckel T, Fitzgerald KA, Latz E, Moore KJ, Golenbock DT. The NALP3 inflammasome is involved in the innate immune response to amyloid-beta. Nat Immunol 2008;9:857-65.

34. Kaushik DK, Gupta M, Kumawat KL, Basu A. NLRP3 inflammasome key mediator of neuroinflammation in murine Japanese encephalitis. PLoS One 2012;7:e32270.

35. Hanamsagar R, Torres $\mathrm{V}$, Kielian $\mathrm{T}$. Inflammasome activation and IL-18/IL-18 processing are influenced by distinct pathways in microglia. J Neurochem 2011;119:736-48.

36. Zhang WH, Wang X, Narayanan M, Zhang Y, Huo C, Reed JC Friedlander RM. Fundamental role of the Rip2/caspase-1 pathway in hypoxia and ischemia-induced neuronal cell death. Proc Natl Acad Sci U S A 2003;100:16012-7.

37. Pelegrin P, Surprenant A. Pannexin-1 mediates large pore formation and interleukin-1beta release by the ATP-gated $\mathrm{P} 2 \times 7$ receptor EMBO J 2006;25:5071-82.

38. Compan V, Baroja-Mazo A, López-Castejón G, Gomez AI Martínez CM, Angosto D, Montero MT, Herranz AS, Bazan E, Reimers D, Mulero V, Pelegrin P. Cell volume regulation modulates NLRP3 inflammasome activation. Immunity 2012;37:487-500.

39. Ramos HJ, Lanteri MC, Blahnik G, Negash A, Suthar MS Brassil MM, Sodhi K, Treuting PM, Busch MP, Norris PJ, Gale M, Jr. IL-1B signaling promotes CNS-intrinsic immune control of West Nile virus infection. PLoS Pathog 2012;8:e1003039.

40. Kummer JA, Broekhuizen R, Everett H, Agostini L, Kuijk L, Martinon F, van Bruggen R, Tschopp J. Inflammasome components NALP 1 and 3 show distinct but separate expression profiles in human tissues suggesting a site-specific role in the inflammatory response. J Histochem Cytochem 2007;55:443-52.

41. Minkiewicz J, de Rivero Vaccari JP, Keane RW. Human astrocytes express a novel NLRP2 inflammasome. Glia 2013;61:1113-21.

42. Tarallo V, Hirano Y, Gelfand BD, Dridi S, Kerur N, Kim Y, Cho WG, Kaneko H, Fowler BJ, Bogdanovich S, Albuquerque RJ, Hauswirth WW, Chiodo VA, Kugel JF, Goodrich JA, Ponicsan SL, Chaudhuri G, Murphy MP, Dunaief JL, Ambati BK, Ogura Y, Yoo JW, Lee DK, Provost P, Hinton DR, Nunez G, Baffi JZ, Kleinman ME, Ambati J. DICER1 loss and Alu RNA induce age-related macular degeneration via the NLRP3 inflammasome and MyD88. Cell 2012;149:847-59.

43. John GR, Lee SC, Song X, Rivieccio M, Brosnan CF. IL-1-regulated responses in astrocytes: relevance to injury and recovery. Glia 2005;49:161-76.

44. Griffin WS, Stanley LC, Ling C, White L, MacLeod V, Perrot LJ, White $\mathrm{CL}, 3^{\text {rd }}$, Araoz C. Brain interleukin 1 and S-100 immunoreactivity are elevated in Down syndrome and Alzheimer disease. Proc Natl Acad Sci U S A 1989;86:7611-5.

45. McGuinness MC, Powers JM, Bias WB, Schmeckpeper BJ, Segal AH Gowda VC, Wesselingh SL, Berger J, Griffin DE, Smith KD. Human leukocyte antigens and cytokine expression in cerebral inflammatory demyelinative lesions of X-linked adrenoleukodystrophy and multiple sclerosis. J Neuroimmunol 1997;75:174-82.

46. Zaremba J, Losy J. Interleukin-18 in acute ischaemic stroke patients. Neurol Sci 2003;24:117-24.

47. Hoegen T, Tremel N, Klein M, Angele B, Wagner H, Kirschning C, Pfister HW, Fontana A, Hammerschmidt S, Koedel U. The NLRP3 inflammasome contributes to brain injury in pneumococcal meningitis and is activated through ATP-dependent lysosomal cathepsin B release. J Immunol 2011;187:5440-51.

48. Mitchell AJ, Yau B, McQuillan JA, Ball HJ, Too LK, Abtin A Hertzog P, Leib SL, Jones CA, Gerega SK, Weninger W, Hunt NH Inflammasome-dependent IFN- $\gamma$ drives pathogenesis in Streptococcus pneumoniae meningitis. J Immunol 2012;189:4970-80.

49. Zwijnenburg PJ, van der Poll T, Florquin S, Akira S, Takeda K, Roord JJ, van Furth AM. Interleukin-18 gene-deficient mice show enhanced defense and reduced inflammation during pneumococcal meningitis. J Neuroimmunol 2003;138:31-7. 
50. Lightfield KL, Persson J, Brubaker SW, Witte CE, von Moltke J, Dunipace EA, Henry T, Sun YH, Cado D, Dietrich WF, Monack DM, Tsolis RM, Vance RE. Critical function for Naip5 in inflammasome activation by a conserved carboxy-terminal domain of flagellin. Nat Immunol 2008;9:1171-8.

51. Lee HM, Kang J, Lee SJ, Jo EK. Microglial activation of the NLRP3 inflammasome by the priming signals derived from macrophages infected with mycobacteria. Glia 2013;61:441-52.

52. Kumar M, Roe K, Orillo B, Muruve DA, Nerurkar VR, Gale M Jr, Verma S. Inflammasome adaptor protein Apoptosis-associated speck-like protein containing CARD (ASC) is critical for the immune response and survival in west Nile virus encephalitis. $J$ Virol 2013;87:3655-67.

53. Mori I, Hossain MJ, Takeda K, Okamura H, Imai Y, Kohsaka S, Kimura Y. Impaired microglial activation in the brain of IL-18-gene-disrupted mice after neurovirulent influenza A virus infection. Virology 2001;287:163-70.

54. Sergerie Y, Rivest S, Boivin G. Tumor necrosis factor-alpha and interleukin- 1 beta play a critical role in the resistance against lethal herpes simplex virus encephalitis. J Infect Dis 2007;196:853-60.

55. Chien H, Dix RD. Evidence for multiple cell death pathways during development of experimental cytomegalovirus retinitis in mice with retrovirus-induced immunosuppression: apoptosis, necroptosis, and pyroptosis. J Virol 2012;86:10961-78.

56. Schielke GP, Yang GY, Shivers BD, Betz AL. Reduced ischemic brain injury in interleukin-1 beta converting enzyme-deficient mice. J Cereb Blood Flow Metab 1998;18:180-5.

57. Boutin H, LeFeuvre RA, Horai R, Asano M, Iwakura Y, Rothwell NJ. Role of IL-1alpha and IL-1beta in ischemic brain damage. J Neurosci 2001:21:5528-34

58. Zheng Y, Humphry M, Maguire JJ, Bennett MR, Clarke MC. Intracellular interleukin-1 receptor 2 binding prevents cleavage and activity of interleukin-1a, controlling necrosis-induced sterile inflammation. Immunity 2013;38:285-95.

59. Keller M, Rüegg A, Werner S, Beer HD. Active caspase- 1 is a regulator of unconventional protein secretion. Cell 2008;132:818-31.

60. de Rivero Vaccari JP, Lotocki G, Alonso OF, Bramlett HM, Dietrich WD, Keane RW. Therapeutic neutralization of the NLRP1 inflammasome reduces the innate immune response and improves histopathology after traumatic brain injury. J Cereb Blood Flow Metab 2009;29:1251-61.

61. Abulafia DP, de Rivero Vaccari JP, Lozano JD, Lotocki G, Keane RW, Dietrich WD. Inhibition of the inflammasome complex reduces the inflammatory response after thromboembolic stroke in mice. J Cereb Blood Flow Metab 2009;29:534-44.

62. Frederick Lo C, Ning X, Gonzales C, Ozenberger BA. Induced expression of death domain genes NALP1 and NALP5 following neuronal injury. Biochem Biophys Res Commun 2008;366:664-9.

63. Adamczak S, Dale G, de Rivero Vaccari JP, Bullock MR, Dietrich WD, Keane RW. Inflammasome proteins in cerebrospinal fluid of brain-injured patients as biomarkers of functional outcome: clinical article. J Neurosurg 2012;117:1119-25.

64. Gris D, Ye Z, locca HA, Wen H, Craven RR, Gris P, Huang M, Schneider M, Miller SD, Ting JP. NLRP3 plays a critical role in the development of experimental autoimmune encephalomyelitis by mediating Th1 and Th17 responses. J Immunol 2010;185:974-81.

65. Inoue M, Williams KL, Gunn MD, Shinohara ML. NLRP3 inflammasome induces chemotactic immune cell migration to the CNS in experimental autoimmune encephalomyelitis. Proc Natl Acad Sci U S A 2012;109:10480-5.

66. Lalor SJ, Dungan LS, Sutton CE, Basdeo SA, Fletcher JM, Mills KH Caspase-1-processed cytokines IL-1beta and IL-18 promote IL-17 production by gammadelta and CD4 T cells that mediate autoimmunity. J Immunol 2011;186:5738-48.

67. Mason JL, Suzuki K, Chaplin DD, Matsushima GK. Interleukin-1beta promotes repair of the CNS. J Neurosci 2001;21:7046-52.

68. Jha S, Srivastava SY, Brickey WJ, Iocca H, Toews A, Morrison JP, Chen VS, Gris D, Matsushima GK, Ting JP. The inflammasome sensor, NLRP3, regulates CNS inflammation and demyelination via caspase-1 and interleukin-18. J Neurosci 2010;30:15811-20.

69. Glass CK, Saijo K, Winner B, Marchetto MC, Gage FH. Mechanisms underlying inflammation in neurodegeneration. Cell 2010;140:918-34.

70. Codolo G, Plotegher N, Pozzobon T, Brucale M, Tessari I, Bubacco L, de Bernard M. Triggering of inflammasome by aggregated a-synuclein, an inflammatory response in synucleinopathies. PLoS One 2013;8:e55375.

71. Shi F, Yang L, Kouadir M, Yang Y, Wang J, Zhou X, Yin X, Zhao D. The NALP3 inflammasome is involved in neurotoxic prion peptide-induced microglial activation. $J$ Neuroinflammation 2012;9:73

72. Craft JM, Watterson DM, Hirsch E, Van Eldik LJ. Interleukin 1 receptor antagonist knockout mice show enhanced microglial activation and neuronal damage induced by intracerebroventricular infusion of human beta-amyloid. $J$ Neuroinflammation 2005;2:15.

73. Shaftel SS, Kyrkanides S, Olschowka JA, Miller JN, Johnson RE, O'Banion MK. Sustained hippocampal IL-1 beta overexpression mediates chronic neuroinflammation and ameliorates Alzheimer plaque pathology. J Clin Invest 2007;117:1595-604.

74. Meissner F, Molawi K, Zychlinsky A. Mutant superoxide dismutase 1-induced IL-1beta accelerates ALS pathogenesis. Proc Natl Acad Sci U S A 2010;107:13046-50

Cite this article as: Xie Z, Zhao G. Pyroptosis and neurological diseases. Neuroimmunol Neuroinflammation 2014;1(2):60-5.

Source of Support: Nil. Conflict of Interest: No.

Received: 11-07-2014; Accepted: 25-07-14 